\title{
Medication Adherence and Clinical Outcomes towards Oral Hypoglycemic Agents among Type II Diabetic Cohort
}

\author{
Mohanraj Rathinavelu Mudaliar,2*, Priyanka Pichala Tejashwani ${ }^{3}$, Ishrar Shaik Mohammad Ghouse ${ }^{3}$, \\ Sahithi Bogireddy ${ }^{3}$, Gavini Siva Bharat ${ }^{3}$, Sasikala Boreddy ${ }^{4}$
}

\author{
${ }^{1}$ Associate Professor, Division of Pharmacy Practice, Raghavendra Institute of Pharmaceutical Education and Research (RIPER), \\ Anantapuramu, Andhra Pradesh - 515721, INDIA. \\ 2Drug Information Pharmacist, Poison and Drug Information Center, Rural Development Trust (RDT) Hospital, Bathalapalli, \\ Anantapuramu, Andhra Pradesh- 515661, INDIA. \\ ${ }^{3}$ Assistant Professor, Division of Pharmacy Practice, Raghavendra Institute of Pharmaceutical Education and Research (RIPER), \\ Anantapuramu, Andhra Pradesh- 515721, INDIA. \\ ${ }^{4}$ Resident Intern, Doctor of Pharmacy Program, Division of Pharmacy Practice, Raghavendra Institute of Pharmaceutical Education and
} Research (RIPER), Anantapuramu, Andhra Pradesh- 515721, INDIA.

\begin{abstract}
Introduction: Clinical outcomes are measurable clinical parameter which predicts the glycemic control of the disease. Poor adherence to oral hypoglycemic agents remains as one of the main reasons for poor metabolic control. Poor self-management of drug therapy may increase the burden of diabetes to the patient. Materials and Methods: The current prospective observational study of six months duration was performed to assess the adherence of oral hypoglycemic agents and clinical outcomes with reference to patient's glycemic level in diabetic outpatients of both genders, age greater than 18 years; in a secondary referral hospital of south India. Results: Out of 90 diabetics, $47.78 \%$ were male and $52.22 \%$ were female; and $37.8 \%$ of patients were aged between 61 - 70 years; and $63.31 \%$ were prescribed with combination of metformin and glibenclamide, when compared to $22.2 \%$ of monotherapy with metformin and the same was directly proportional to their mean medication possession ratio. Our study observed $83.3 \%$ of patients were non-adherent to therapy based on their medication possession ratio value, the results also showed that there is significant difference between clinical outcomes in patients based on medication compliance. It was observed that for every $10 \%$ increase in medication possession ratio there was improved glycemic control and also significant difference of charlson comorbidity index among patients who are adherent and nonadherent. Conclusion: In conclusion, correlating adherence towards medication use could be a tool to improve and maintain healthoutcomes and quality of life in diabetic cohort populations.
\end{abstract}

Key words: Adherence, Charlson comorbidity index, Medication possession ratio, Oral hypoglycemic agents, Outcomes.

\section{INTRODUCTION}

Nonadherence to medications is a common problem in clinical practice, especially among patients with asymptomatic chronic conditions such as diabetes, hypertension and hypercholesterolemia. ${ }^{1-3}$ Nonadherence to medication is associated with increased hospitalization, progression of disease and higher mortality. ${ }^{4-5}$ However, only about $50 \%$ of patients with chronic conditions take their medications as prescribed..$^{6-7}$

Adherence to diabetes medications is generally poor. ${ }^{8-9}$ Several studies have demonstrated a link between adherence
DOI: 10.5530/ijopp.11.4.39

Address for correspondence: Dr. Mohanraj Rathinavelu Mudaliar. Pharm.D, Associate Professor and Internship Coordinator, Doctor of Pharmacy Program, Division of Pharmacy Practice, Raghavendra Institute of Pharmaceutical Education and Research (RIPER), Anantapuramu, Andhra Pradesh 515721, INDIA.

Phone no: +91 8121934940 Email Id: moley4u@rediffmail. com

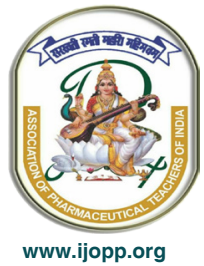


and diabetes-related outcomes, including A1C levels. ${ }^{10-12}$ A recent meta-analysis has showed that the average adherence in patients with diabetes is $67.5 \%$, which is lower than that found among many conditions..$^{13}$ Also, recently, a specific systematic review on adherence to medications for diabetes showed that average adherence to oral hypoglycemic agents ranged from 36 to $93 \%{ }^{14}$

Studies in India indicates that more than $50 \%$ of people with diabetes have poor glycemic control (HbA1c $>8 \%$ ), uncontrolled hypertension and dyslipidemia and a percentage have diabetic vascular complications. ${ }^{15}$

Research has demonstrated that adherence can lead to lower health care utilization and total costs, ${ }^{16-17}$ and is associated with better health outcomes and decreased risk of hospitalization. ${ }^{17-18}$

Oral hypoglycemic agents (OHAs) are the major treatment options for T2DM patients and these drugs helps to improve glycemic control and decrease disease progression towards complications such as nephropathy and retinopathy. Medication non-adherence may explain the suboptimal achievement of therapeutic targets. ${ }^{5}$

However, poor adherence to OHAs remains as one of the main reasons for poor metabolic control. Poor selfmanagement of drug therapy may increase the burden of diabetes to the patient. ${ }^{19-20}$ Only $37.7 \%$ of the patients treated with OHAs have glycosylated hemoglobin $(\mathrm{HbA} 1 \mathrm{c})<7 \%{ }^{21}$

Adherence to medications is not routinely measured in clinical practice and a gold standard that can be easily implemented, even for research purposes, does not exist. $^{22}$

Adherence may be measured indirectly or directly. Two indirect adherence metrics used in research and administrative work are the medication possession ratio (MPR) and the proportion of days covered (PDC). MPR is calculated as the total number of days supplied, divided by the number of days between the first and last refills; while PDC is calculated as the total number of days supplied during an interval, divided by the total number of days during that interval. ${ }^{23}$ An MPR of $80 \%$ is often used as the cut off between adherence and nonadherence based on its ability to predict hospitalizations across selected high prevalence chronic diseases. ${ }^{24}$

The MPR is calculated by dividing the total days' supply of the medication by the total number of days within the period of analysis. ${ }^{25}$ This calculation is used to evaluate how much medication a patient received over a period of observation, compared to the amount the patient should have ideally obtained. ${ }^{25}$ A MPR equal to one represents absolute adherence and serves as a benchmark. ${ }^{26}$

Clinical outcomes are measurable clinical parameter which predicts the glycemic control of the disease. In this study we considered FBS, PPBS and RBS as clinical outcome parameters. For instance, prescription refill adherence to diabetes medications correlates with improved hemoglobin A1C results. Similarly, adherence to blood sugar self-monitoring is also associated with lower HbA1c levels as is adherence to diet and lifestyle change. ${ }^{27}$

Not many studies on medication adherence among diabetic patients have been documented in rural Indian healthcare settings. Hence, the current research study was designed to assess the adherence of OHAs and clinical outcomes with reference to patient's glycemic level.

\section{MATERIALS AND METHODS}

\section{Study design}

Prospective observational study.

\section{Study site}

Department of general medicine of a secondary referral healthcare setting in south India.

\section{Study duration}

Six months (January - June 2016).

\section{Study criteria}

Outpatients of general medicine department of both genders, age greater than 18 years; diagnosed with type II diabetes mellitus (with or without complications), who are on OHAs were included and patients on insulin for glycemic control and who have not refilled the prescription for at least once during the study period and pregnant women were excluded from the study.

\section{Study population}

A total of 90 diabetic subjects satisfying the inclusion criteria's were enrolled in the study.

\section{Ethical approval}

The ethical approval was obtained from the Ethical Committee before the commencement of study. 


\section{Study procedure}

The current prospective, observational study of six months duration was performed in Type II diabetic out-patients attending general medicine department for refill of prescriptions (only with OHAs) of a secondary care referral hospital in south India.

A structured process was followed in obtaining permission from hospital authority by submitting a detailed profoma of the study, which includes protocol of study, evidence of critically evaluated biomedical literatures, data collection form, patient informed consent form. After the initial acceptance from hospital authority, study was registered in the institutional review board (IRB) of the institution for ethical approval (RIPER/IRB/2016/009) and institutional ethics committee of hospital.

A total of 90 diabetic subjects satisfying the inclusion criteria's and showing willingness were enrolled in the study. A documentation form (data collection form) was designed to collect the individual patient demographic particulars, laboratory parameters of glycemic control (FBS, RBS and PPBS) and treatment regimen which were kept confidential, information from patients were collected only after explaining and making them understand about the merits and demerits of the study, consent from patients was obtained before their recruitment and the consent was further documented.

\section{Statistical and Data Analysis}

The data's obtained from patients were thoroughly analyzed to evaluate the adherence towards oral antidiabetics and clinical outcomes through medication possession ratio (MPR). ${ }^{25}$

Student $t$ test was used to determine significant difference between clinical outcomes of adherent and non-adherent patients. Furthermore, the Charlson Comorbidity Index $(\mathrm{CCI})^{28}$ expressing the degree of comorbidity at any time during follow-up, was also assessed.

\section{RESULTS}

The study was based on evaluating the adherence of OHAs and clinical outcomes with reference to glycemic level in 90 patients attending the outpatient department of general medicine of a secondary referral healthcare setting in south India.

\section{Demographic details of study participants}

In our study, out of 90 patients $43(47.78 \%)$ were male and $47(52.22 \%)$ were female; and $33(37.8 \%)$ of

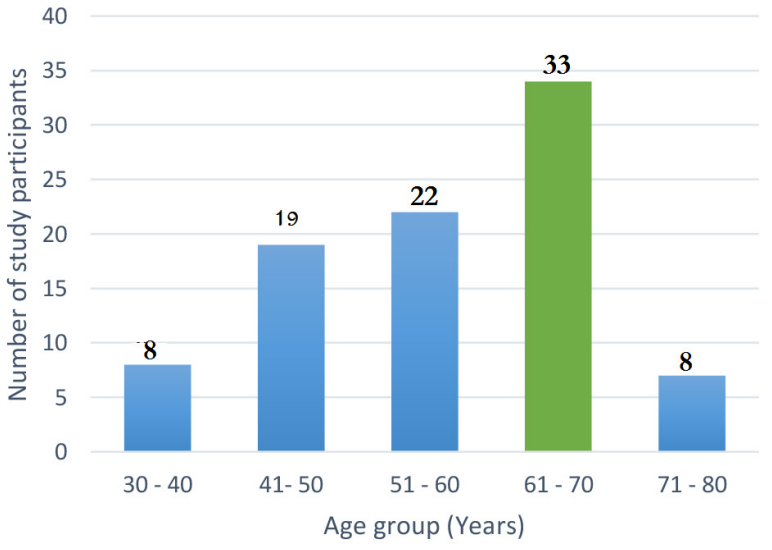

Figure 1: Demographic distribution of study participants.

patients were aged between 61 - 70 years, results of which are thoroughly analyzed and reported in Figure 1

Demographic distribution of study participants.

\section{Comparison of adherence and non-adherence with outcome parameters}

The current study observed, twenty five patients were adherent and sixty five patients were non-adherent based on the medication possession ratio. The mean MPR observed in adherence patients was $83.3 \pm 2.8$ and $53.9 \pm 3.7$ in non-adherence patients which was found statistically significant $(P$ value $=0.0009$ and the charlson comorbidity index (CCI) for the adherent patients were found to be less in comparison to non-adherent patients which was observed statistically significant $(\mathrm{P}<0.001)$; results of which are analyzed and reported in Table 1 Comparison of adherence and non-adherence with outcome parameters.

\section{Oral Antidiabetics prescribed in study participants $(n=90)$}

In our study, $63.31 \%$ were prescribed with combination

\begin{tabular}{|c|c|c|c|}
\hline Variables & Adherence & $\begin{array}{c}\text { Non- } \\
\text { adherence }\end{array}$ & $P$ value \\
\hline $\begin{array}{l}\text { Number of } \\
\text { patients }\end{array}$ & 25 & 65 & \\
\hline $\begin{array}{l}\text { MPR (Mean + } \\
\text { SD) }\end{array}$ & $83.3+2.8$ & $53.9+3.7$ & 0.0009 \\
\hline $\begin{array}{c}\text { FBS (Mean + } \\
\text { SD) }\end{array}$ & $113.08+12.3$ & $165.34+36.4$ & $<0.009$ \\
\hline $\begin{array}{l}\text { PPBS (Mean } \\
+ \text { SD) }\end{array}$ & $154.69+40.5$ & $260.37+54.55$ & $<0.0015$ \\
\hline $\begin{array}{c}\mathrm{CCl} \text { (Mean + } \\
\text { SD) }\end{array}$ & $2.6+1.7$ & $2.9+1.7$ & $<0.001$ \\
\hline
\end{tabular}

( $P$ value $<0.05$ is considered as statistically significant student $t$ test) 


\begin{tabular}{|c|c|c|}
\hline Therapy & $\begin{array}{c}\text { Number of } \\
\text { patients (\%) }\end{array}$ & $\begin{array}{c}\text { Mean MPR } \\
(\%)\end{array}$ \\
\hline Monotherapy (Metformin) & $20(22.2)$ & 76.3 \\
\hline $\begin{array}{c}\text { Dual therapy (Metformin }+ \\
\text { glibenclamide) }\end{array}$ & $57(63.31)$ & 60.4 \\
\hline$>2$ drugs & $13(14.4)$ & 45 \\
\hline
\end{tabular}

of metformin and glibenclamide, when compared to $22.2 \%$ of monotherapy with metformin and the same was directly proportional to their mean MPR observed, results were thoroughly assesses and reported in Table 2 Oral Antidiabetics prescribed in study participants.

\section{DISCUSSION}

In diabetes, as with other chronic conditions, successful prevention of the long term clinical manifestations of disease requires a lifetime treatment with medication. Although randomized clinical trials are keystone of clinical decision making, adherence to medication therapy is a key factor in translation of clinical trial efficacy to real world effectiveness. To this end, both clinicians and health policy decision makers could benefit from a vigorous understanding of the issues affecting the links between adherence and various outcomes. The current research represents clear evidence in diabetes, linking adherence to clinical outcomes.

Based on the literature, better adherence was found to be associated with improved glycemic control and decreased health care resource utilization. ${ }^{29}$ In our study, for every $10 \%$ increase in MPR, glycemic control of $17.77 \mathrm{mg} / \mathrm{dl}$ (FBS) and 35.94 (PPBS) was observed; and adherence towards monotherapy $(76.3 \%)$ was far better in comparison to dual therapy but not optimum. Regarding the OHAs treatment, no significant difference was observed in the glycemic control from either the single drug or two drugs or more than two drugs. Probably it is true that use of more medications is not associated with better glycemic control. ${ }^{21}$ Similar kind of result was obtained in another study which also emphasizes that more oral medications, rather is a marker for a greater likelihood of poor control. ${ }^{30}$ Only by increasing the number of medicines might not improve glycemic control. There are various confounding factors that have effect on the glycemic control. Our study also observed among individuals still being treated after a year, 22\% were non-compliant, in whom the MPR observed was less than $80 \%$. However, the mean MPR observed was $86.3 \%$ results of which are similar to the findings of Guenette $\mathrm{L}$ et al. $2013 .{ }^{31}$ At the end of our study, $83 \%$ of total study participant was non-adherent with MPR less than $80 \%$.

Additional status about clinical status confirmed that $36 \%$ of patients were re-hospitalized for diabetic ketoacidosis showing poorest adherence.

\section{Limitations}

The findings of the current research has to be reinforced and simulated, with larger sample size and regular follow-ups; to improve their external validity and the non-existence of gold standards in measuring adherence is a evident limitations.

\section{CONCLUSION}

In conclusion, treatment non-compliance is being increasingly recognized as one of the major limitations to improve healthoutcomes; and measurement of adherence is associated with improving and maintaining health outcomes and quality of life in patients with diabetes.

\section{ACKNOWLEDGEMENT}

The authors convey would like to thank the management and staff members and ethical committee members of Rural Development Trust (RDT) Hospital, Bathalapalli, Anantapuramu, Andhra Pradesh, India.

\section{CONFLICT OF INTEREST}

The author declares no Conflict of Interest

\section{ABBREVIATIONS}

CCI: Charlson Comorbidity Index; FBS: Fasting Blood Sugar; HbA1c: Glycated Hemoglobin; IRB: Institutional Review Board; MPR: Medication Possession Ratio; OADs: Oral Anti Diabetics; OHAs: Oral Hypoglycemic Agents; PDC: Proportion of Days Covered; PPBS: Post Prandial Blood Sugar; RBS: Random Blood Sugar; RIPER: Raghavendra Institute of Pharmaceutical Education and Research; T2DM: Type 2 Diabetes Mellitus.

\section{REFERENCES}

1. Dunbar JJ, Mortimer SMK. Treatment adherence in chronic disease. J Clin Epidemiol. 2001; 54(12):S57-60

2. Haynes RB, McDonald H, Garg AX, Montague P. Interventions for helping patients to follow prescriptions for medications (Review). Cochrane Database Syst Rev..2002;(2):CD000011.

3. Sabate E. Adherence to long-term therapies: evidence for action. Geneva, World Health Org. [article online]. Accessed 5 March 2004. Available from http://www.who.int/chronic_conditions/adherencereport/en 
4. Doggrell SA. Adherence to medicines in the older-aged with chronic conditions: does intervention by an allied health professional help? Drugs Aging. 2010; 27(3):239-54

5. Michael HP, Rumsfeld JS, Masoudi FA, et al. Effect of medication nonadherence on hospitalization and mortality among patients with diabetes mellitus. Arch Intern Med. 2006; 166(17):1836-41.

6. Kronish IM, Ye S. Adherence to cardiovascular medications: lessons learned and future directions. Prog Cardio-vasc Dis. 2013; 55(6):590-600.

7. Burkhart PV, Sabate E. Adherence to long-term therapies: evidence for action. J Nurs Scholarsh. 2003; 35(3):207.

8. Cramer JA, Roy A, Burrell A, Fairchild CJ, Fuldeore MJ, Ollendorf DA, et al. Medication compliance and persistence: terminology and definitions. Value Health: J Int Soc Pharmacoecon Outcomes Res. 2008; 11(1):44-7.

9. Lee WC, Balu S, Cobden D, Joshi AV, Pashos CL. Prevalence and economic consequences of medication adherence in diabetes: a systematic literature review. Manag Care Interface. 2006; 19(7):31-41.

10. UK Prospective Diabetes Study (UKPDS) Group. Intensive blood-glucose control with sulphonylureas or insulin compared with conventional treatment and risk of complications in patients with type 2 diabetes (UKPDS 33). Lancet. 1998; 352(9131):837-53

11. Currie CJ, Peyrot M, Morgan CL, Poole CD, Jenkins Jones S, Rubin RR, et al. The impact of treatment noncompliance on mortality in people with type 2 diabetes. Diabetes Care. 2012; 35(6):1279-84.

12. Wild $\mathrm{H}$. The economic rationale for adherence in the treatment of type 2 diabetes mellitus. Am J Manag Care. 2012; 18(3): S43-8.

13. Matteo MRPD. Variations in patients' adherence to medical recommendations: a quantitative review of 50 years of research. Med Care. 2004; 42:200-9.

14. Cramer JA. A systematic review of adherence with medications for diabetes. Diabetes Care. 2004; 27:1218-24.

15. James HDK, David SHB, Kathleen LW. Overview of Diabetes Mellitus. Diabetes Essential. Third edition. 2007;3-11.

16. Roebuck MC, Liberman JN, Gemmill TM, Brennan TA. Medication adherence leads to lower health care use and costs despite increased drug spending. Health Aff. (Millwood). 2011; 30(1):91-9.

17. Toy EL, Beaulieu NU, McHale JM, et al. Treatment of COPD: relationships between daily dosing frequency, adherence, resource use and costs. Respir Med 2011; 105(3):435-41.
18. Pittman DG, Tao Z, Chen W, Stettin GD. Antihypertensive medication adherence and subsequent healthcare utilization and costs. Am J Manag Care. 2010; 16(8):568-76.

19. Tripathi KD. Insulin, Oral hypoglycemic drugs and Glucagon. Essential of Medicine Pharmacology. $7^{\text {th }}$ edition, 254-74.

20. Kathleen F, Brenda M. Evaluating the medication adherence. Journal of Managed care Pharmacy. 2000; 6(6):499-505.

21. Shrestha SS, Shakya R, Karmacharya BM, Thapa P. Medication adherence to oral hypoglycemic agents among type 2 diabetic patients and their clinical outcomes with special reference to fasting blood glucose and glycosylated haemoglobin levels. Kathmandu Univ Med J (KUMJ). 2013; 43(3); 226-36.

22. Vitolins MZ, Rand CS, Rapp SR, RibisI PM, Sevick MA. Measuring adherence to behavioral and medical interventions. Control Clin Trials. 2000; 21(5):188-94

23. LA Fleur J, Oderda GM. Methods to measure patient compliance with medication regimens. J Pain Palliat Care Pharmacother. 2004; 18(3):81-7.

24. Karve S, Cleves MA, Helm M, Hudson TJ, West DS, Martin BC. Good and poor adherence: Optimal cut-point for adherence measures using administrative claims data. Curr Med Res Opin. 2009; 25(9):2303-10.

25. Fairman K, Motheral K. Evaluating Medication Adherence: Which Measure is Right for Your Program? J Manage Care Pharm. 2000; 6(6):499-504.

26. Christian S Conley, Peter JH. Medication adherence of patients assistance program recipients. A pilot study. Innovations in Pharmacy Practice Journal. 2012;3(3):1-11

27. Joel M. Schectman, John B. Schorling, John DV. Appointment Adherence and Disparities in Outcomes among Patients with Diabetes. J Gen Intern Med. 2008; 23(10):1685-7.

28. Charlson score: http://touchcalc.com/calculators/cci_js-online

29. Asche C, Fleur JL, Conner C. A review of diabetes treatment adherence and the association with clinical and economic outcomes. Clin Ther. 2011; 33(1)74-109.

30. Wagner EH, Grothaus LC, Sandhu N. Chronic care clinics for diabetes in primary care: a system-wide randomized trial. Diabetes Care. 2001; 24(4):695-700.

31. Guénette L, Moisan J, Breton MC, Sirois C, Grégoire JP. Difficulty adhering to antidiabetic treatment: factors associated with persistence and compliance. Diabetes Metab. 2013; (3):250-7 